\title{
The effects of concept mapping on student nurses' learning of medical-surgical nursing
}

\author{
Sze Wing Julia Wong*1, Baaska Anderson ${ }^{2}$, Martin Gough ${ }^{2}$ \\ ${ }^{1}$ School of Nursing, Tung Wah College, Hong Kong, China \\ ${ }^{2}$ University of Liverpool, Liverpool, United Kingdom
}

Received: December 3, 2019

Accepted: March 17, 2020

Online Published: March 25, 2020

DOI: $10.5430 /$ jnep.v10n7p1

URL: https://doi.org/10.5430/jnep.v10n7p1

\begin{abstract}
Background and objective: Many student nurses are weak in studying medical-surgical nursing because higher-order skills are required to understand and incorporate prior knowledge with new knowledge. Hence, this study tried to employ concept mapping (CM) in teaching one medical-surgical nursing course to enhance their learning. The aims of this study are to explore the effects on student nurses' learning experience and examine the difference in academic performance of students who learned this subject by using $\mathrm{CM}$ and those who did not.

Methods: This was a mixed research study conducted in 2017. The overall grade and pass rate were used to compare the differences between $\mathrm{CM}$ and non-CM groups. Moreover, focus group discussions after semesters were used to explore the impact of CM on student nurses' learning.

Results: The difference of marks between the CM group $(M=77.90$ and $S D=8.09)$ and non-CM group $(M=57.56$ and $S D=$ 10.16) was statistically significant ( $p=.000$ ) with a large effect (Cohen's $d=2.21$ ). Twenty-six student nurses were interviewed in focus group discussions. The advantages and shortcomings of $\mathrm{CM}$ were identified. After new and prior knowledge was bridged, students used their own perceived effective method to re-organise knowledge and enhance their memory to prepare for written examinations.

Conclusions: To conclude, CM seems able to improve students' academic performance, and students gained a good understanding of the relationships between concepts in medical-surgical nursing, especially for the students who were new to the subject. The results of this study will provide insights for nurse educators who teach Chinese student nurses.
\end{abstract}

Key Words: Concept mapping, Nursing education, Medical-surgical nursing, Collaborative learning

\section{INTRODUCTION}

Medical-surgical nursing is a core subject that is arranged as a series of four courses over a five-year bachelor nursing programme in Hong Kong. However, passing rates are relatively low compared with other nursing courses. It is a critical component of a bachelor nursing programme and a crucial element in the nursing profession because students learn the signs and symptoms of diseases, diagnostic tests, medical treatment and corresponding nursing interventions. This body of knowledge provides foundations for their clini- cal practice. Many student nurses have informally reflected difficulty in comprehending medical-surgical nursing knowledge because higher-order and critical thinking skills are required. ${ }^{[1]}$ This reason is acceptable because students are first required to understand and incorporate new knowledge into prior knowledge, for example, anatomy and physiology. Student nurses should analyse biological, psychological and sociological influences in patients, and corresponding nursing interventions should be implemented. Furthermore, nursing interventions embody a five-step nursing process, which

*Correspondence: Sze Wing Julia Wong; Email: juliawong@twc.edu.hk; Address: School of Nursing, Tung Wah College, Hong Kong, China. 
includes assessment, diagnosis, outcome/planning, intervention and evaluation. Consequently, students are expected to formulate a nursing care plan with a holistic approach.

In the studied School of Nursing, nurse educators are accustomed to using conventional PowerPoint lectures in classrooms, and scenario-based exercises are given to students to discuss and answer in tutorial sessions. Students are required to self-study using textbooks. Consistently low passing rates and informal students' feedback suggest that the current teaching method may not help students to understand the relationship between prior knowledge and new knowledge. Hence, educators have been looking for an appropriate teaching method for tackling this problem. Concept map (CM) might be a good choice.

$\mathrm{CM}$ is 'a two-dimensional schematic device for representing a set of concept meanings embedded in a framework of propositions' ${ }^{[2]}$ It was developed by Joseph Novak in 1972 based on David Ausubel's assimilation theory of meaningful learning and the concept of constructivism and scaffold learning. ${ }^{[3]} \mathrm{A} \mathrm{CM}$ is structured in a hierarchical form, which creates meaningful learning by linking up the relationships between concepts with arrows and connective words. ${ }^{[4,5]}$ The structure of a CM enables knowledge to be retained in learners' memory for long periods of time as our memory organises knowledge in a hierarchical order, which helps enhance our learning capacity. ${ }^{[5,6]}$

In nursing education, numerous studies have found a statistically significant improvement in student nurses' criticalthinking skills when CMs are used to develop nursing care plans $^{[7-9]}$ as well as in their problem-solving skills. ${ }^{[10]}$ Therefore, animated concept mapping with PowerPoint slides was adopted in a medical-surgical course, trying to facilitate the incorporation of new knowledge into prior knowledge. ${ }^{[3]}$ The aims of this study were to evaluate the effectiveness of $\mathrm{CM}$ on academic performance and explore its effects on the learning of student nurses.

\section{MethodS}

\subsection{Research questions}

1) Is there a difference in pass rate and overall grade in medical-surgical nursing courses between students who were taught this subject by using CM and those who were not?

2) Is there a difference in overall grade between the first and re-takers?

3) What are the students' perceptions of using CM to learn medical-surgical nursing, and do their perceptions differ based on sensory modalities?

\subsection{Research design}

This was a mixed research study conducted in the academic year 2016/17. The overall grade and pass rate were used to compare the differences between $\mathrm{CM}$ and non-CM groups. Moreover, focus group discussions after semesters were used to explore the impact of $\mathrm{CM}$ on student nurses' learning.

\subsection{Participants}

All of the participants in this study were local (Hong Kong) people. The targeted students were second- or third-year student nurses pursuing a five-year nursing degree programme in the researched institute and who had enrolled in the same medical-surgical course. Given that CM was introduced to students who enrolled for this course in the spring and summer semesters, two CM groups were established. Students who enrolled for the same course in the preceding winter semester were used retrospectively for comparison. Hence, this group of students was named the non-CM group.

\subsection{Study procedures}

Firstly, the course teacher used animated CM with PowerPoint slides to deliver lectures. Relevant learning materials were delivered to students as usual. A corresponding 1-hour tutorial session was held 1-2 weeks after the lecture. In the tutorial session, students were asked to form groups of five to six. Then, they were given 20 minutes to identify the patient's problem in the scenario and use CM to outline the corresponding nursing interventions with their classmates. The tutors then selected one group of students to present their CM. Afterwards, the tutors showed the model answers with a pre-constructed CM in PowerPoint presentation with animation to the students. In order to maintain the consistency of tutors involved in the tutorial sessions, the following measures were taken: 1) pre-constructed $\mathrm{CM}$ was prepared by one teacher, 2) model answers in written form and preconstructed CM were distributed to all the tutors one week before each tutorial, and 3) briefing sessions on the use of $\mathrm{CM}$ were held before the tutorials. The researchers of this study were not involved in teaching this course.

\subsection{Focus group interviews}

Regarding the recruitment of focus group interviewees, a participant information sheet and consent form were sent to all the students in the CM groups through their school email accounts in the last week of the spring and summer semesters. After receiving the replies from students who were interested in participating in the study, a 45-minute semi-structured focus group interview was arranged after the examination period which was around two weeks after the end of the semester. All the interviews were audio recorded with consent obtained. The guiding questions of the inter- 
views were as follows:

1) Can you describe what happened when you and your classmates were asked to form groups and answer the scenariobased questions with $\mathrm{CM}$ in the tutorial sessions? What was your feeling with regard to this method?

2) When your view was different from that of your classmates, what did you do?

3) Could it help you in learning the course? If yes, how? If no, why?

4) How did you prepare for the mid-term test/exam?

\subsection{Ethical consideration}

The ethical approval of this study was obtained from the Committee on the Use of Human and Animal Subjects in Teaching and Research (HASC) of the researched institute. Besides, the Registrar's approval of using de-identified students' academic results was also obtained before implementation of the study. In addition, informed consent was obtained from the participants before conducting the focus group interviews.

\subsection{Data analysis}

International Business Machine (IBM) Statistical Product and Service Solutions for Windows version 23.0 ${ }^{[11]}$ was used to analyse the quantitative data, whereas the qualitative data collected from the focus group interviews were audiorecorded and then transcribed verbatim. Eventually, they were coded and categorised by using thematic analysis. ${ }^{[12]}$

\subsection{Trustworthiness}

To ensure the trustworthiness of the qualitative data, the verbatim was transcribed by the professionals and counterchecked by the researcher. In addition, two researchers conducted the thematic analysis individually and then discussed it in meetings to reach compromise and finalise the identified themes.

\section{RESUlts}

\subsection{Quantitative results}

The total number of recruited students was $241(M=49$, $F=192)$ in the winter semester, $109(M=31, F=78)$ in the spring semester and $90(M=24, F=66)$ in the summer semester. The released final grades provided by the Registry were used for analysis. The pass rate of this course increased from $77.6 \%$ in the winter semester to $100 \%$ in both the spring and summer semesters. The average grades were 57.56 (SD $=10.16), 79.72(S D=7.07)$ and $75.69(S D=8.72)$ in the winter, spring and summer semesters, respectively. One-way ANOVA test (see Table 1) indicated statistical significance with large differences between winter and spring ( $p=.000$; Cohen's $d=2.532$ ), as well as the winter and summer groups ( $p=.000$; Cohen's $d=1.915$ ) at the 0.05 level, and less statistical significance $(p=.006)$ was observed with medium difference (Cohen's $d=.508$ ) between the spring and summer groups. The results suggest that average grades in both CM groups were statistically significantly higher than those in the non-CM group, and the magnitude of differences was large. Furthermore, although students' overall grade in the spring CM group was statistically significantly higher than that in the summer CM group, the magnitude of difference was medium. ${ }^{[13,14]}$ When the spring and summer groups were combined as one CM group and compared with the non-CM group, the pass rates were $100 \%$ and $77.59 \%$, respectively. The difference of marks between the CM group $(M=77.90$ and $S D=8.09)$ and non-CM group $(M=57.56$ and $S D=10.16)$ was statistically significant $(p=.000)$ with a large effect (Cohen's $d=2.21$ ). Overall, CM can likely help improve students' academic performance.

Table 1. Differences in overall grades between semesters

\begin{tabular}{|c|c|c|c|c|c|}
\hline & $N$ & $M(S D)$ & {$[95 \% \mathrm{CI}]$} & $\bar{p}$ & Cohen's $d$ \\
\hline Winter Semester (non-CM) & 241 & $57.56(10.16)$ & {$[56.27,58.84]$} & & \\
\hline Spring Semester & & & & .000 & 2.532 \\
\hline Summer Semester & & & & .000 & 1.915 \\
\hline Spring Semester (CM) & 109 & $79.72(7.07)$ & {$[78.38,81.06]$} & & \\
\hline Winter Semester & & & & .000 & 2.532 \\
\hline Summer Semester & & & & .006 & 0.508 \\
\hline Summer Semester (CM) & 90 & $75.69(8.72)$ & {$[73.86,77.52]$} & & \\
\hline Winter Semester & & & & .000 & 1.915 \\
\hline Spring Semester & & & & .006 & 0.508 \\
\hline
\end{tabular}

Note. $M=$ mean; $S D=$ standard deviation; $\mathrm{CI}=$ confidence interval.

Comparisons of average grades between the first and second takers within groups using independent sample $t$-test were also conducted (see Table 2). The total numbers of first and second takers in the non-CM group were 205 (85\%) and 36 
(15\%), respectively, and their mean overall grades were 55.78 $(S D=9.56)$ and $67.70(S D=7.13)$, respectively. By contrast, the total numbers of first and second takers in the CM group were $110(55.3 \%)$ and $89(44.7 \%)$, respectively, and their mean overall grades were $79.14(S D=7.46)$ and $76.36(S D$ $=8.60$ ), respectively. The results shows a statistical significance with very large difference in the non-CM groups ( $p$ $=.000$; Cohen's $d=1.413$ ). This finding indicates that the re-takers performed significantly better than the first takers, and the magnitude of difference was very large. However, the results may not be able to reflect the truth because the number of first-takers in the non-CM groups was more than six times that of re-takers. Moreover, statistical significance with a small difference was observed in the CM groups ( $p=$ .016; Cohen's $d=0.344$ ). This finding means that the first takers' academic performance in the CM group was significantly better than that of the re-takers, but the magnitude of difference was small.

Table 2. Differences in overall grade for first and second takers within semesters

\begin{tabular}{|c|c|c|c|c|}
\hline & $N(\%)$ & $M(S D)$ & $p$ & Cohen's d \\
\hline \multicolumn{5}{|c|}{ Winter Semester (non-CM) } \\
\hline First taker & 205 (85\%) & $55.78(9.56)$ & .000 & 1.413 \\
\hline Second taker & $36(15 \%)$ & $67.70(7.13)$ & & \\
\hline \multicolumn{5}{|c|}{ Spring \& Summer Semester (CM) } \\
\hline First taker & $110(55 \%)$ & $79.13(7.46)$ & .016 & 0.344 \\
\hline Second taker & 89 (45\%) & $76.36(8.60)$ & & \\
\hline
\end{tabular}

Note. $M=$ mean; $S D=$ standard deviation; $\mathrm{CI}=$ confidence interval.

When the overall grades of the first and second takers between non-CM and CM groups were compared (see Table 3 ), the first takers' mean overall grades in the non-CM and $\mathrm{CM}$ groups were $55.78(S D=9.56)$ and $79.14(S D=7.46)$, respectively. Thus, the second takers' mean overall grades in the non-CM and $\mathrm{CM}$ groups were $67.70(S D=7.13)$ and $76.36(S D=8.60)$, respectively. The results reveal a statisti- cal significance with a very large difference in the first taker groups ( $p=.000$; Cohen's $d=2.723$ ). This finding means that the first takers in the $\mathrm{CM}$ group performed significantly better than those in the non-CM group, and the magnitude of difference was very large. Moreover, a statistical significance with a large difference was observed in the re-taker groups $(p=.000 ;$ Cohen's $d=1.096)$.

Table 3. Differences in overall grade for the first and second takers between semesters

\begin{tabular}{|c|c|c|c|c|}
\hline & $N(\%)$ & $M(S D)$ & $p$ & Cohen's $d$ \\
\hline \multicolumn{5}{|l|}{ First taker } \\
\hline Winter semester (non-CM) & 205 (65\%) & $55.78(9.56)$ & .000 & 2.723 \\
\hline Spring \& Summer Semester (CM) & $110(35 \%)$ & $79.13(7.46)$ & & \\
\hline \multicolumn{5}{|l|}{ Second taker } \\
\hline Winter semester (non-CM) & $36(29 \%)$ & $67.70(7.13)$ & .000 & 1.096 \\
\hline Spring \& Summer Semester (CM) & $89(71 \%)$ & $76.36(8.60)$ & & \\
\hline
\end{tabular}

Note. $M$ = mean; $S D$ = standard deviation; $\mathrm{CI}$ = confidence interval.

\subsection{Qualitative findings}

A total of 26 students were interviewed in groups. All participants in the spring semester had enrolled for this course for the first time, but eight out of nine participants in the summer semester were re-takers as they failed in the previous academic year. The transcribed verbatim was coded and categorised into the following five themes.

\subsubsection{Advantages of using $C M$}

Students agreed that CM shows the relationships between nursing problems and interventions in a comprehensive, systematic and well-organised manner through categorisation and summarisation. This form of presentation provides them with a clear and overall picture in a short period, so students find it easy to grasp the relationships between concepts because it simplifies the complicated concepts into a simple and understandable diagram. In light of these advantages, CM enhances students' understanding of topics, facilitates their learning and promotes good memorisation.

'A CM presents the relationship between concepts in short form which is easy to read and memorise.'

'The CM categorises the nursing problems in different aspects which helps me to understand it easily.'

'The CM used in this course helps me to understand the topic more systematically.' 


\subsubsection{Impacts on group work}

During group discussions in the tutorial sessions, students learned from their classmates because they would help provide information, despite missing some points whilst drawing the concept map. Thus, some misconceptions can be clarified through arguing with classmates and further verification with the tutor in the tutorial sessions. However, the degree of groupmates' engagement was also a key component to determine the outcome of learning from the group activity because some of the students reported that some of their groupmates did not actively participate in drawing the concept map or made no input to the discussion. In this area, feedback was mainly received from the first-takers. CM in group work seems ineffective for the re-takers as they reported that they had learnt the content in their first take and their understanding of knowledge had been further enhanced during their first clinical practicum. Hence, their engagement in group discussion was less than that of the first takers.

'The discussions with classmates in drawing the concept map in tutorial sessions help my memorisation because conversa tion is stored longer in my memory.'

'The discussions in tutorial sessions help me to learn deeper about the topic because everybody has his/her own thinking and learning styles... we may miss some points, then through the discussions, and we can supplement each other.'

'I like group discussion with CMs rather than studying alone because the CM provides plenty of room for discussion. The arguments among classmates help to clarify my misconcep tions and I can learn the right concepts and more than when alone.'

\subsubsection{Stimulation of thinking}

A few students shared that $\mathrm{CM}$ provides them another way of thinking, it broadens their way of thinking, and the keywords and lines drive them to think further. In addition, they also expressed that drawing a concept map is similar to the way they think. Positive feedback was received from both the first takers and re-takers.

'Drawing a concept map just like our way of thinking in the brain...It provides more directions to think.'

'It is a very good tool; it drives me to think more.'

'CM is good for memorising complex knowledge; the lines of CM helped stimulate my thinking'

\subsubsection{Disadvantages of CM and preparation approach for the written examination}

In this area, students shared their approaches for preparing for the written examination, which was held at the end of the semester. In their sharing, a few disadvantages of CM, such as its extensiveness, time-consuming, confusing and too simple nature, were also identified.

Published by Sciedu Press
Few learners used CM in learning new knowledge, doing revision and preparing for examinations; however, many of them only used it at the end of revision or just before the examination. The conventional nursing care plan format was preferred instead; that is, the students re-organised the content from PowerPoint slides and textbooks into table and point forms instead of $\mathrm{CM}$, because the conventional nursing care plan is relatively not time-consuming. Furthermore, students can easily prioritise the nursing interventions from specific to general in a top-down format as the format of $\mathrm{CM}$ is like a spider web, which cannot fulfil their needs. Thus, they think that the prioritisation of nursing interventions is very important in nursing. Hence, table or point form layouts were displayed from top to bottom, so they were only confined to a standard paper size and can be stored in piles. By contrast, the CM coverage can be considerably extensive, which easily confused them. The extensive CM can only be read with a tablet or computer, which caused further inconvenience.

I tried to use CM before this semester but I gave up very soon because the size of paper was not big enough for me to write, even though I used A3 paper; therefore, I went back to using point form writing from top to bottom.'

'I would not use it for studying because it is very timeconsuming to draw a concept map and it can be very big. I prefer to write the nursing interventions one by one and then prioritise them by numbering each intervention... the lines in CM causes my thinking to jump here and there, and I feel it is very messy.'

'The CM is very big...quite confusing sometimes and we cannot prioritize the interventions in CMs... and there are keywords only... too short... no elaboration of the nursing interventions.'

In addition, students were concerned about the rationales behind nursing interventions. However, only keywords were provided in CM. Consequently, students performed revision by reading the PowerPoint notes provided by lecturers and textbooks for the written examination held at the end of the semester. Some students even re-wrote them in table form for revision because they thought that the effect of using CM and table forms is similar to writing a nursing care plan but only with a different layout. A few of the students expressed that the numerous lines in CM caused confusion. Hence, they used their own structured methods to memorise nursing interventions and rationales as they thought that this is the best strategy to attain a passing or good grade in the examination. Such findings were commonly found for both first takers and re-takers.

'Sometimes too many lines seem messy so I write the nursing 
interventions in list form for revision.'

'I like to use CMs in class but I like to write the nursing interventions in essay form while doing revision because CMs are quite fragmented. I need to lay out things one by one.'

'In revision, I make my own notes in table and point forms after reading the textbook and PowerPoint notes. I only read my own notes for the written exam.'

Some students were re-takers, and they underwent the first clinical practicum after their first admission to the course. Therefore, when they retook this course, they found that their clinical experience, instead of CM, helped them to understand the topics. These re-takers also expressed that $\mathrm{CM}$ is not an important tool. They only used it for consolidation after the revision and for a quick look just before the examination. Thus, they thought that their last failure was not related to their understanding of knowledge but to their lack of preparation for the examination. Although the re-takers did not need CM to bridge knowledge for them, it helped them with better memorisation. To conclude, CM likely can be used in different stages of their learning process. It all depends on the learners' needs.

'Last time I had not started my clinical practicum yet but after coming back from the first clinical practicum, I found it easy to understand the course content...practical experience helped my understanding of diseases and corresponding interventions.'

'During the examination, after I read the scenario, I would imagine if I was the patient, how s/he would be. Thus, the previous experience in clinical practice helped my understanding of the patient in the scenario.'

'Since I already understand the relationships very well, I would only use CM at the last moment for revising the whole concept.'

\subsubsection{Effective way of using CM}

The CM tool only provides keywords, and students suggested that lecturers should add short sentences to elaborate the rationales of nursing interventions. CM should only be black and white and confined to printable paper sizes. In addition, students, as learners, showed uncertainty about the accuracy of their work when they were asked to draw a concept map in tutorial sessions. Hence, lecturers were asked to provide a debriefing on CM again at the end of tutorial sessions. Detailed model answers should also be provided. PowerPoint presentations should be used as the primary learning tool by lecturers, and CM with animation should be used as a supplementary teaching tool.

'A few phrases listed under the key concept can provide guidance for us to look up the relevant areas in the textbook...at least then we have some ideas to follow.'

'The size of CM would be better confined to a standard paper size... not too big... with some key points as the elaboration of the key concept... that's perfect!'

'Only using CM is not workable I think. . but it is good when the teacher provides the detailed model answers after debriefing with CM as this method provides me a clear train of thought.'

\section{DiscuSSION}

The image of CM mimics the learners' way of thinking inside the brain, and it links the concepts in a systematic and well-organised manner for a short period, which enhances the comprehension of relationships between concepts and promotes memorisation in long-term memory. Additionally, a concept map was drawn to answer scenario-based questions with groupmates during tutorial sessions, further enhancing and consolidating the understanding of knowledge. Although collaborative learning can trigger learners' learning mechanism through interaction with one another, educators may not be able to guarantee that the expected interactions will actually occur within the group because the effort or engagement by the learner depends on his/her own control. ${ }^{[15]}$ Nevertheless, an educator at least can create a collaborative learning environment and act as a facilitator in the group discussions to increase the probability of interaction.

The narrative results of this study are in accordance with previous literature. ${ }^{[16-18]}$ Thus, the preference of students to use traditional care plans is also found in the findings of Hinck et al. ${ }^{[17]}$ This phenomenon may be attributed to the presence of a preconceived notion as textbooks and nursing care plans use traditional table formats. Whether or not students use CM when preparing for examinations, their common behaviour is to use their perceived effective strategy to consolidate and memorise the context in order to attain the best outcome, that is, good examination results. The students' behaviour reflected that the optimal effect of CM mainly occurs upon initial contact with new knowledge. Once the learners overcome the hurdle of understanding the troublesome knowledge, they re-organise the learnt knowledge with their habitual learning method for better memorisation. In addition, the introduction of $\mathrm{CM}$ provided a new insight of learning and way of thinking to students, so that some of them used it in different ways when preparing for examinations and further extended its application to their daily life or other courses.

Both quantitative and qualitative results showed that $\mathrm{CM}$ has a significant effect in regard to learning medical-surgical nursing courses, particularly when synthesising knowledge and when student nurses are first-time enrolees on a course. This phenomenon may echo Haugwitz, Nesbit, and Sandmann, and Patterson, Dansereasu, and Wiegmann, who eluci- 
dated that CM is only effective for learners with low cognitive ability, as the map characteristics may develop conflicts with the strategies that high-ability learners usually employ, or, high-ability learners have already reached their cognitive functional ceiling. ${ }^{[19,20]}$ In this study, although the students' cognitive ability was not measured, the explanation is that the first-takers need extra time and cognitive load to comprehend new knowledge compared with re-takers. In this sense, their cognitive ability to handle new knowledge is lower than that of re-takers. This may explain why most of the re-takers found $\mathrm{CM}$ useless.

Although students may or may not use CM for their examination, the following strategies are suggested to use CM effectively for bridging the chunks of knowledge: use CM at the end of lectures to summarise the taught knowledge, provide an opportunity for students to draw a concept map collaboratively to answer scenario-based questions and provide debriefing with $\mathrm{CM}$ after group exercises.

\section{Strengths \& Limitations}

The results of this study provide insights for nurse educators on how to teach Chinese student nurses with CM effectively. However, a few limitations also existed. First, the teaching content, teachers and questions in the written examinations of non-CM and CM groups were not exactly the same. Second, only one non-CM group was used retrospectively to compare the pass rate. Third, numerous extrinsic and intrinsic factors, such as motivation, self-efficacy, stress, study time, familyand teacher-related factors etc. can affect one's academic performance. ${ }^{[21]}$ Fourth, given the extreme imbalance of sample size between the first-takers and re-takers in the non$\mathrm{CM}$ group, gender and number of re-takers in both non-CM and CM groups, a few of the comparisons may not be able to reveal the true reality. The abovementioned confounding variables may have potential influences on the results.

\section{Conclusion}

In view of there being scant studies about the effectiveness of using CM in Chinese student nurses, the results of this study provide empirical evidence to nurse educators that using CM with collaborative learning is likely an effective and economical method to enhance student nurses' learning of medical-surgical nursing. Moreover, the students' feedback also gives insight on the skills of employing CM in classroom teaching which enables the educators to use it productively.

\section{Reccomendation}

To prove the potential of this tool, researchers should explore it further with large samples in relation to other medical-surgical courses. Using a cross-sectional survey to evaluate the whole class' perception of using $\mathrm{CM}$ is recommended. Thus, a longitudinal study of the long-term effects of CM is also suggested. Lastly, the current conclusion is drawn under the assumption that humans think with a spider-like network. If different types of thinking systems exist, it may can explain why $\mathrm{CM}$ affects learners differently.

\section{CONFliCts OF INTEREST Disclosure}

The author declares that there is no conflict of interest.

\section{REFERENCES}

[1] Kaddpura M, Van-Dyke O, Yang Q. Impact of a concept map teaching approach on nursing students' critical thinking skills. Nursing and Health Sciences. 2016; 18: 350-354. PMid:26891960 https://doi.org/10.1111/nhs. 12277

[2] Novak JD, Gowin DB. Learning how to learn. Cambridge University Press, New York. 1984.

[3] Novak JD. Learning, creating, and using knowledge: Concept maps as facilitative tools in school and corporations. Journal of e-Learning and Knowledge Society. 2010; 6(3): 21-30.

[4] Akinsanya C, Williams M. Concept mapping for meaningful learning. Nurse Education Today. 2003; 24: 41-46. https ://doi .org/10.1 016/S0260-6917(03) 00120-5

[5] Novak JD. Concept maps and Vee diagrams: two metacognition tools to facilitate meaningful learning. Instructional Science. 1990; 19: 1-25. https://doi.org/10.1007/BF00377984

[6] Novak JD, Wandersee J. Coeditors, special issue on concept mapping. Journal of Research in Science Teaching. 1991; 28(10).

[7] Atay S, Karabacak Ü. Care plans using concept maps and their effects on the critical thinking dispositions of nursing students. International
Journal of Nursing Practice. 2012; 18: 233-239. PMid:22621292 https://doi.org/10.1111/j.1440-172X.2012.02034.x

[8] Lee W, Chiang CH, Liao IC, et al. The longitudinal effect of concept map teaching on critical thinking of nursing students. Nurse Education Today. 2013; 33: 1219-1223. PMid:22795871 https : //doi.org/10.1016/j.nedt.2012.06.010

[9] Moattari M, Soleimani S, Moghaddam NJ, et al. Clinical concept mapping: Does it improve discipline-based critical thinking of nursing students? Iranian Journal of Nursing and Midwifery Research. 2014; 19(1): 70-76.

[10] Tseng HC, Chou FH, Wang HH, et al. The effectiveness of problembased learning and concept mapping among Taiwanese registered nursing students. Nurse Education Today. 2011; 31(8): 41-46. PMid:21159411 https://doi.org/10.1016/j.nedt.2010.11 .020

[11] IBM Corp. Released. IBM SPSS Statistics for Windows, Version 22.0. Armonk, IBM Corp., New York. 2013.

[12] Braun V, Clarke V. Using thematic analysis in psychology. Qualitative Research in Psychology. 2006; 3(May 2015): 77-101. https : //doi.org/10.1191/1478088706qp063oa 
[13] Bartolucci AA, Tendera M, Howard G. Meta-analysis of multiple primary prevention trials of cardiovascular events using aspirin. American Journal of Cardiology. 2011; 107(12): 1796-801. PMid:21481826 https://doi.org/10.1016/j.amjcard.2011.02.325

[14] Coe R. It's the effect size, stupid: what "effect size" is and why it is important. Paper presented at the 2002 Annual Conference of the British Educational Research Association, University of Exeter, Exeter, Devon, England. 2002. Available from: http://www . leed s.ac.uk/educol/documents/00002182.htm

[15] Dillenbourg P. What do you mean by collaborative learning?, in P. Dillenbourg (Ed), Collaborative-learning: Cognitive and computational approaches. Elsevier, Oxford; 1999; 1-19.

[16] Harrison S, Gibbons C. Nursing student perceptions of concept maps: From theory to practice. Nursing Education Perspective. 2013; 34(6): 395-399. PMid:24475601 https ://doi.org/10.5480/10-465

[17] Hinck SM, Webb P, Sims-Giddens S, et al. Student learning with concept mapping of care plans in community-based education. Jour- nal of Professional Nursing. 2006; 22(1): 23-29. PMid:16459286 https ://doi.org/10.1016/j.profnurs .2005.12.004

[18] Kostovich CT, Poradzisz M, Wood K, et al. Learning style preference and student aptitude for concept maps. The Journal of Nursing Education. 2007; 46(5): 225-231. PMid:17547346 https : //doi.org/10.3928/01484834-20070501-06

[19] Haugwitz M, Nesbit J, Sandmann A. Cognitive ability and the instructional efficacy of collaborative concept mapping. Learning and Individual Differences. 2010; 20(5): 536-543. https://doi.org/ 10.1016/j.lindif. 2010.04.004

[20] Patterson ME, Dansereau DF, Wiegmann DA. Receiving information during a cooperative episode: Effects of communication aids and verbal ability. Learning and Individual Differences. 1993; 5: 1-11. https://doi.org/10.1016/1041-6080(93)90022-K

[21] Shawwa LA, Abulaban AA, Merdad A, et al. Factors potentially influencing academic performance among medical students. Advances in Medical Education and Practice. 2015; 6: 65-75. PMid:25674033 https://doi.org/10.2147/AMEP.S69304 